\section{Iván Karamázov: héroe-ideólogo}

\author{
Silvia Méndez Anchía*
}

\section{RESUMEN}

Este artículo presenta un análisis de la novela Los Hermanos Karamázov, de Fedor Dostoievski. Su referente teórico es el planteamiento de Mijail Bajtín, uno de los más reconocidos estudiosos de la obra dostoievskiana. Tiene como hilo conductor el personaje de Iván, que es propuesto como un héroe-ideólogo, es decir, aquel cuya caracteristica fundamental es la autoconciencia. Estudia cómo la idea de Iván "Si Dios no existe, todo está permitido" se presenta como un "acontecimiento vivo" gracias al encuentro dialógico de varias conciencias: la del propio Iván con Smerdiákov, con el diablo, con Dmitri y Aliosha. Se concluye que cada personaje ha corrido su suerte en función del diálogo con la idea de Iván Karamázov.

\section{PALABRAS CLAVE}

Novela polifónica, Dostoievski, Hermanos Karamazov, literatura rusa, realismo

* Bachiller en Filología Española por la Universidad de Costa Rica y licenciada en Ciencias de la Educación con Énfasis en Docencia por la Universidad Estatal a Distancia. Máster en Psicopedagogía. Filóloga y docente. Productora académica en la Universidad Estatal a Distancia.

Rec. 10-5-05 / Acep. 28-9-05

\section{ABSTRACT}

This article analyzes the novel The Karamazov Brothers written by Fedor Dostoievsky. Its theoretical reference is based on Mijail Bajtin's thoughts. Batjin is one of the most recognized experts of Dostoievsky's work. Its theme is based on the character of Ivan, who is presented as an ideologist hero; in other words, his main characteristic is the self-awareness. This article is based on how Ivan's idea of "If God does not exist everything is permitted" is presented as a "real event" due to the dialogical encounter of Ivan's with: Smerdiakov, with the devil, with Dmitri and with Alioska. We can conclude the each character has stated his own destiny based on Ivan Karamazov's idea of the function of the dialogue.

\section{KEY WORDS}

Polyphonic novel, Dostoievsky, Karamazov Brothers, Russian Literature, Realism

\section{INTRODUCCIÓN}

En Dostoievski vemos que el hombre es deseo, crisis, pasión, pecado, arrepentimiento. Sometido a los impulsos más tenebrosos y con un ansia de vivir de recuperar la vida. Hay un destino y una fatalidad, y una libertad que se logra de manera ardua como enfrentamiento al vacío y al absurdo.

Sonia Cruz

La obra de Dostoievski es genial, lo mismo que la de Cervantes, Shakespeare y Tolstoi. Y mucho de su genialidad se debe a que ha sido fuente de discusiones, principalmente en el plano ideológico, y sigue dando pie al debate filosófi- 
co en nuestros días. La actualidad de la polémica que genera su obra, podemos ilustrarla con el ensayo Dostoievski en Manhattan, de André Glucksmann (2002), quien reflexiona, con ocasión del ataque terrorista del 11 de setiembre del 2001, acerca de las actitudes nihilistas y la responsabilidad de gobernantes y ciudadanos.

Estamos, pues, ante un escritor en cuya obra se enfrentan las grandes cuestiones que preocupan a la humanidad. En diciembre de 1877, Dostoievski anunció que empezaría a escribir una novela en la cual trataría de plasmar un problema que lo había atormentado durante toda su vida: la existencia de Dios.

De Los Hermanos Karamázov, ese último monumento de la obra dostoeivskiana -que para muchos representa la máxima expresión de su dominio de la novela, así como de su profundidad psicológica-, surge un héroe: Iván. En torno a ese personaje haremos esta lectura de la novela.

Natalia Ujánova (2003) ha señalado que la imagen de Iván es la más importante de esta obra desde la perspectiva ideológica y filosófica, por su naturaleza complicada y contradictoria. Este personaje será el hilo conductor por medio del cual nos aproximaremos al resto de los personajes, en ese encuentro dialógico de las ideas, de las conciencias, de los textos, que es la polifonía dostoievskiana.

Para los teóricos Shlovski y Bajtín, el dialogismo constituye el sistema de composición fundamental de la obra de Dostoievski. Shlovski lo plantea en los siguientes términos:

Las controversias no ocurren sólo entre los personajes; los diferentes elementos del desarrollo del tema están también, de alguna forma en conflicto: los hechos son interpretados dialogísticamente, la psicología de los personajes se contradice; esta forma emana del propio principio de Dostoyevski (citado por Marchese y Forradellas, 2000:99).

Esta forma de composición textual lleva implícita una visión del ser humano, el cual sólo se puede definir con base en las relaciones que establece con los otros. Debido a su incapacidad para verse de manera total, la persona necesita el contacto con otras que le completen esa imagen (Amoretti, 1992).

Veremos, seguidamente, ese contacto de personajes alrededor de la figura de Iván y cómo este se 
va transformando a partir de una idea que no permanece inmutable, sino que cobra vida también en el discurso y las acciones de los demás personajes.

\section{Iván Karamázov, un héroe-ideólogo}

El mundo artístico de Dostoievski, lo mismo que su creador es 'pura lucha'.

Es un mundo de pensamientos $y$ de búsquedas plenas de tensión.

Tatiana Ujánova

Según Bajtín (1986), el héroe de las obras de Dostoievski se presenta, ante todo, como un punto de vista acerca del mundo y de sí mismo. Tal concepción exige una representación singular del personaje, de quien lo que aparece no es un determinado modo de ser, producto de un ente acabado, sino más bien su palabra como recuento último de su conciencia.

Hallamos una circunstancia peculiar en la presentación que de Iván hace el narrador: mientras que Aliosha, Dmitri, Fiodor y hasta Smerdiákov se presentan, en algún momento, por sus rasgos físicos, Iván no. De Alexiéi se dice, por ejemplo, que es "un adolescente de diecinueve años, de buena figura, colorado de cara, de mirada luminosa, rebosante de salud [...] muy hermoso, esbelto, más bien alto que bajo, de cabello castaño, de rostro regular" (p. 37).1 Dmitri se nos presenta como "un joven de veintiocho años, de estatura media y rostro agradable. Era musculoso, se adivinaba que poseía una notable fuerza física" (p. 87). De Iván, por el contrario, desde el inicio se destaca únicamente su cáracter: sombrío y encerrado en sí mismo; con una percepción muy clara, para su edad, de su condición de huérfano, de desposeído.

En cuanto al mayor, Iván, diré tan sólo que creció como un adolescente sombrío y encerrado en sí mismo; sin ser tímido ni mucho menos, pero como si ya a los diez años hubiera comprendido que, de todos modos, los dos crecían en casa ajena y gracias a la ajena limosna, que su padre era un tal y un cual, del que hasta hablar resultaba vergonzoso; etcétera, etcétera (p. 25).

Lo principal, pues, de esta visión del héroe es la autoconciencia, la cual no constituye un atributo

1. Todas las citas textuales tomadas de la novela Los Hermanos Karamázov corresponden a la edición de Bruguera de 1983. Por razones de economía discursiva, toda vez que aludamos a ese texto citaremos únicamente el número de página. Al final de este artículo se presenta la referencia bibliográfica completa. 
más, sino que se convierte en la representación última del personaje. De ahí que Dostoievski someta a sus personajes a lo que Bajtín llama "peculiares torturas morales", para que el discurso de su autoconciencia llegue a expresarse profundamente.

Este héroe autoconsciente nunca aparece concluido; de ello se desprende la particular fuerza de un Iván, de un Raskolnikof, de un Dmitri, pues "Un hombre permanece vivo [señala Bajtín, 1986, p. 87], por el hecho de no estar aún concluido y de no haber dicho todavía su última palabra".

En el "Prólogo" de Los Hermanos Karamázov, el autor señala esta característica como resultado de un momento histórico en el cual es difícil mantener una posición definida. Así, al reflexionar acerca de Alexiéi, lo cataloga como un hombre de acción indefinida, ya que "de todos modos sería raro exigir de los hombres claridad en un tiempo como el nuestro" (p. 9). Aquí abrimos un paréntesis para comentar el hecho de que Dostoievski propone a Alexiei como el "protagonista" de su novela, lo cual resulta ser un claro ejemplo de que la intencionalidad del autor no constituye un criterio al cual podamos recurrir con certeza para la interpretación (D’Alton, 1990); si bien es cierto, para el autor, Aliosha es el personaje central (pues probablemente representa el punto de vista manifiesto de Dostoievski), la lectura que aquí presentamos propone a Iván, con su preocupación filosófica, como el centro del texto.

Siguiendo con el tema de la dificultad de tener una posición definida en una época de indefinición, el héroe aparece, en su ser inconcluso, en una constante relación con ese mundo al que intenta aprehender mediante su discurso. Según Bajtín (1986, p. 112), “el héroe no es solamente un ser consciente, sino un ideólogo", es decir, que su palabra abarca, además de su ser interno, la representación del mundo circundante.

Estamos, entonces, frente a una idea que no está resuelta, inseparable de la imagen inconclusa del personaje portador de tal idea. Esta situación se pone en evidencia en el diálogo que sostiene Iván con el stárets Sozima. Al referirse a su planteamiento acerca de la existencia de la virtud, Iván reconoce, en las palabras del stárets, esa particular irresolución que lo domina. Veamos:

" - No lo ha dicho del todo en broma, cierto. Esta idea todavía no ha quedado 
resuelta en su corazón y lo tortura. [...] Usted no tiene aún resuelta dicha cuestión y en ello radica su amargura, pues exige una solución perentoria...

- ¿Pero puede resolverse, en mi caso? ¿Puede resolverse en sentido positivo? - continuó preguntando de manera extraña Iván Fiódorovich, sin dejar de mirar al stárets con inexplicable sonrisa.

- Si no puede resolverse en sentido positivo, tampoco se resolverá nunca en sentido negativo, usted mismo conoce esta propiedad de su corazón; y en esto radica toda su congoja" (pp. 90-91).

Ahora bien, este héroe-ideólogo, además de presentarse de manera inconclusa, con una idea no resuelta, adquiere su verdadera fuerza sólo al entrar en contacto con otros personajes, cuyas conciencias dialogarán con la suya en igualdad de condiciones. De este modo, el diálogo que establece Iván con el resto de personajes de la novela, es parte de una relación entre conciencias inconclusas con visiones de mundo no resueltas. Así lo señala Bajtín: "El autor sólo puede contraponer a la conciencia del héroe que lo absorbe todo, un único mundo objetual que es el de otras conciencias equitativas" (1986:75).

Los diálogos cobran vida al exponerse desde la polémica que se da al interior mismo de los personajes. Por ejemplo, después del asesinato de Fiodor, Iván conversa con Aliosha y le pregunta si cree que Dmitri es el asesino de su padre. Aliosha le responde que él (Iván) no es el asesino. Aquí el joven novicio habla con una de las partes del diálogo interno de Iván, justamente con aquella que quiere condenarlo por sus ideas, que vendrían a justificar el parricidio.

La idea, pues, no aparece en abstracto. Por el contrario, se presenta como un "acontecimiento vivo", gracias al encuentro dialógico de varias conciencias. Esta intensa vida de las ideas en el encuentro dialógico de los héroes-ideólogos, viene a cumplir una función de reconocimiento en el discurso del otro, que, como apunta Bajtín (1986), es el recurso más importante en la poética de Dostoievski:

Esta trasposición del discurso de una boca a otra, en la que los enunciados de un mismo contenido cambian de tono y de su último sentido, representa el procedimiento principal de Dostoievski. El escritor obliga a sus persona- 
jes a reconocerse a sí mismos, su idea, su propia palabra, su orientación, su gesto en el otro hombre, en el cual todas estas manifestaciones cambian su sentido total y conclusivo, suenan de otra manera, como una parodia o una burla" (pp. 103-104).

La formulación de Iván Karamázov "Si Dios no existe, todo está permitido", se halla presente a lo largo de la novela, no solo en su propio discurso, sino también en el del resto de los personajes, con los diversos acentos y sentidos que cada uno de ellos le va confiriendo; incluso trasciende el nivel intratextual, para pasar a formar parte, años más tarde, de discusiones filosóficas como la que se plantea en El hombre rebelde, de Camus.

"Iván es un enigma", nos dice su hermano Aliosha, el novicio. Iván aparece, de esta forma, como un personaje en el cual confluyen los demás para descifrar su secreto (Berdiaev, 1978). Este joven llega a casa de Fiodor, su padre, a petición de Dmitri, quien desea que su hermano actúe como mediador entre él y su padre, pues sospecha que Fiodor se ha apropiado de unos dineros que le corresponden a él. Iván, pues, viene a cumplir un objetivo determinado, pero su idea abarcará todo el texto, para adoptar múltiples formas, que llegan hasta su actualización. El narrador mismo señala la expectación que generó la llegada de Iván a la ciudad: "No obstante, incluso cuando tuve noticia de esa especial circunstancia, Iván Fiódorovich siguió pareciéndome enigmático y su llegada a nuestra ciudad, pese a todo, inexplicable" (p. 28).

Como los demás personajes de esta obra se van definiendo en el discurso de los otros, así Iván va siendo presentado por Aliosha, por Piotr Alexándrovich, por Rakitin, por Sozima, de modo que -de estas muchas visiones- se va construyendo en los otros, en quienes despierta especial interés por sus ideas.

Aliosha cree que su hermano se ocupa de algo interior e importante: "Iván es un hombre de alma agitada. Tiene la mente cautiva de un gran pensamiento, todavía sin aclarar. Él es de los que no necesitan millones, sino poner en claro su pensamiento" (p. 104). Piotr Alexándrovich, por su parte, cuenta una anécdota acerca de Iván, en la cual se expone, por vez primera en esta novela, la idea de que el amor no es producto de ninguna ley natural, sino que depende de la creencia en la inmortalidad; al desaparecer esta creencia, todo estará permitido. En este pasaje, 
el diálogo es retomado por Dmitri, para quien es de gran importancia comprender esta frase:

Permítame -exclamó de pronto Dmitri Fiódorovich, gritando-, por si lo he oído mal: 'El crimen no sólo ha de ser considerado lícito, sino que incluso ha de ser reconocido como la salida más necesaria y juiciosa de la situación en que se encuentra todo ateo'. ¿Es así? (p. 90)

Para Rakitin, el "seminarista ambicioso", el planteamiento de Iván resulta un acertijo tonto: "iToda su teoría es una infamia! ¡La humanidad encontrará en sí misma la fuerza de vivir para la virtud, aun sin creer en la inmortalidad del alma!" (p. 104).

Sírvannos los anteriores ejemplos como nota introductoria a la idea propuesta por Iván y a las reacciones que provoca en los demás personajes. En ellos se resume, en forma apretada, la problemática que se nos plantea con este héroe dostoievskiano.

\section{Una idea: "Si Dios no existe, todo está permitido"}

\section{El mal: la injusticia de Dios}

El mal, entendido como el sufrimiento de los inocentes (es decir, ese mal que no puede considerarse como castigo por un pecado), desencadena en Iván el juicio del plan divino. Así lo plantea este personaje:

\begin{abstract}
...si todos hemos de sufrir para comprar con nuestro sufrimiento la eterna armonía, ¿qué tienen que ver con ello los niños? [...] Es totalmente incomprensible por qué han de sufrir ellos también y por qué han de contribuir con sus sufrimientos al logro de la armonía" (p. 300).
\end{abstract}

De este modo -y tal como señala Camus- Dios pasa a ocupar el banquillo de los acusados: Iván lo juzga entonces y lo condena, pues no acepta que su Creación, la cual Él conoce en todos sus extremos, conlleve el sufrimiento de los inocentes. Para Iván, es una Creación inaceptable. Sobre Dios, él apela a un principio más alto, cual es la Justicia. Con ello, sustituye el Reino de la Gracia por el de la Justicia. 
Al solidarizarse con los condenados -"todos o nadie"-, Iván rechaza la inmortalidad. De modo que, al no haber inmortalidad, no habrá virtud ni ley; por tanto, "todo estará permitido".

Iván instaura, así, la posibilidad de enjuiciar al Padre (llámese Fiodor o Dios); al mismo tiempo, instaura la rebelión contra ese principio de autoridad, pese a no considerarse un "sublevado" y a considerar que la sublevación conlleva una imposibilidad de vivir.

Ahora bien, es conveniente señalar aquí que estas ideas de Iván son enunciadas, desde un inicio, en forma ambigua. Hay que destacar, al respecto, el carácter condicional de la expresión "Si Dios no existe, todo está permitido". Es, pues, un razonamiento que exige que se cumpla una condición, en este caso indemostrable, como es la cuestión de la existencia de Dios. Se trata de un problema de fe, ante el cual el razonamiento seguido por Iván mostrará múltiples fisuras a lo largo del texto, proceso que se agudizará desde el momento del crimen.

Nuestro héroe rechaza el plan divino, mas no rechaza con ello la existencia de Dios. Quiere vivir, aunque considere imposible vivir sublevado.
- [...] Muy alto han puesto el precio de la armonía, no es para nuestro bolsillo pagar tanto por la entrada. Me apresuro, pues, a devolver el billete de entrada. [...] No es que no admita a Dios, Aliosha; me limito a devolver respetuosamente el billete.

- Esto es una sublevación - replicó Aliosha, en voz queda y bajando los ojos.

- ¿Una sublevación? No desearía de ti semejante palabra - dijo con calor Iván. ¿Se puede vivir sublevado? Yo quiero vivir" (pp.301-302).

\section{La libertad del ser humano}

Con la "Leyenda del Gran Inquisidor" se ilustra el problema de la libertad. Iván aboga por la libre conciencia de la persona. Se opone a cualquier forma de dominación, aunque tenga como fin la felicidad.

A lo largo de la novela, se establece un paralelismo entre Iván Karamázov y la figura de Cristo. $\mathrm{Al}$ rechazar las tres tentaciones del diablo (el poder por el misterio, el milagro o la autoridad), Cristo actúa, como Iván, en defensa de la libertad del individuo. Iván, como Cristo, se impone una misión que ha de cumplir hasta el 
final: “...ipuestos los labios en esta copa ya no los quitaré hasta apurarla!" (p. 283).

El aprecio de Iván por los niños y su desvalimiento puede extenderse a la figura inocente de Cristo. Al igual que los niños que menciona Iván, Cristo es otro hijo que sufre por los errores del Padre; es otra víctima del precio que hay que pagar para el logro de la armonía. Iván atribuye al plan de Dios el sufrimiento, siempre injustificado, de los niños, los cuales, a su parecer, no deben ser solidarios en el pecado de los padres.

Comprendo la solidaridad de los hombres en el pecado. También la comprendo en el castigo, pero no se puede hacer solidarios a los niños en el pecado, y si la verdad está en que ellos son, en efecto, solidarios con sus padres en todas las atrocidades por estos cometidas, tal verdad no es, desde luego, de nuestro mundo, y a mí me resulta incomprensible (p. 300).

De acuerdo con Iván, el plan de Dios comprende el mal y la muerte. Dios sería, entonces, culpable por ello. Cristo aparece, de esta forma, como la víctima expiatoria que viene a hacerse cargo de estos dos problemas. Dice Camus que "sólo el sacrificio de un dios inocente podía justificar la larga y universal tortura de la inocencia"

(1984:31).

Recordemos, llegados a este punto, que Iván actúa como mediador entre el padre y su hermano Dmitri, de la misma forma que Cristo aparece como intermediario entre Dios Padre y sus hermanos menores, los hombres. Mas, a diferencia de Cristo, Iván no participa de los designios de su padre; al contrario, los cuestiona. Si Cristo vino a instaurar una nueva relación de amor entre Dios y la humanidad, Iván vino a disolverla, para instaurar la rebelión, aunque, como señalamos antes, esta posición es bastante ambigua en este héroe.

\section{La contradicción}

\section{en la idea de Iván}

El planteamiento del "todo está permitido" nace de una rebelión contra un Dios que es juzgado por el ser humano como injusto, ya que su plan de armonía se basa en el sufrimiento y la muerte de los inocentes.

Iván se coloca del lado de la humanidad, tratando de comprenderla en lo que ella es para sí misma, y no a partir del lugar que ocupa en el plan divino. Por eso apunta Berdiaev que a Dostoievski no le obsesiona la teología, sino la 
antropología: “...el gran arte de Dostoievski ha sido poner de manifiesto la agitación oculta que conmueve el subsuelo de la naturaleza humana" (1978:15).

No obstante, al proponer la libertad del ser humano, Iván produce una seria contradicción en su idea: lleva la libertad a tal extremo que justifica el crimen. A partir de este momento, el responsable del mal ya no será Dios; el mal aparecerá, más bien, como producto de la libertad humana. Ese proceso puede esquematizarse de la siguiente forma:

LIBERTAD - ARBITRARIEDAD - MAL - CRIMEN

Según Berdiaev (1978), la libertad, al tornarse arbitraria, conlleva su propia destrucción: "Aquí [en Los Hermanos Karamázov] se manifiesta de manera genial que la libertad como arbitrariedad y autoafirmación conduce necesariamente a la negación no solamente de Dios sino también del hombre, del mundo y de la libertad misma" (p. 65). Camus (1984) lo plantea en estos términos:

Iván se rebela contra un Dios homicida, pero desde el instante en que razona su rebelión deduce la ley del homicidio. Si todo está permitido, puede matar a su padre, o por lo menos sufrir que le maten. Una larga reflexión sobre nuestra situación de condenados a muerte termina únicamente con la justificación del crimen (p. 52).

Justamente esta contradicción en la idea de Iván, esta no resolución que señalaba el stárets Sozima, le confiere a su voz una gran vitalidad: la ambigüedad que notábamos en los primeros discursos del héroe seguirá un proceso de desintegración de la idea, para dar lugar a distintos desdoblamientos (con Smerdiákov, con el diablo) y a diálogos con Aliosha y con Dmitri, entre otros.

Veamos, ahora, el tejido que se forma a la luz de lo propuesto por Iván. Su idea irá adquiriendo sentidos varios, será utilizada con diversos fines, entre ellos para un hecho central en la obra: el asesinato del padre.

\section{La idea: su vida en Iván y en otros personajes}

Hemos seleccionado cuatro momentos que consideramos fundamentales en el proceso de autoconciencia de Iván a partir de su reconocimiento en el discurso de los otros: las tres entrevistas que sostiene con Smerdiákov, su 
encuentro con el diablo, los efectos de su palabra en Dmitri y el diálogo con Aliosha.

\section{Iván y Smerdiákov}

Después del asesinato de Fiodor, Iván regresa de Moscú y conversa en tres ocasiones con Smerdiákov. Recordemos que este admira a Iván $\mathrm{y}$, en cierta forma, lo emula, hecho que molesta al joven Karamázov al verse retratado en un personaje tan vil. A lo largo de esas entrevistas, Iván va viéndose no solo reflejado, sino también "caricaturizado" en el lacayo.

Smerdiákov señala una primera afinidad entre ambos: la cobardía. Reclama a Iván el haber huido de casa del padre, justo cuando se presentaba el momento propicio para el crimen. Cuando Iván le pregunta si cree que todo el mundo es tan cobarde como él, es decir, como Smerdiákov, el lacayo le responde: "Perdone, yo creía que usted sí era como yo" (p. 732).

Luego de su primera entrevista con Smerdiákov después del asesinato de su padre, Iván empieza a reconocer, en las observaciones que el criado le formula, sentimientos de los que él no era consciente.

La utilización de Smerdiákov como un doble de Iván Karamázov tiene como fin conducir a este último hacia un proceso gradual de autoconciencia, que no necesariamente implica la resolución de su carácter o de su idea; más bien, parece hacerle más evidente su confusión $\mathrm{y}$, por ende, su tormento.

Así, después de este primer encuentro, Iván empieza a sentirse torturado por extraños pensamientos asociados con su deseo de dar muerte al padre. Recuerda cómo, antes de partir, había vigilado sigilosamente, "como un ladrón", los movimientos de su padre y cómo, ya en Moscú, se sintió por ello miserable.

Otro punto en común entre Smerdiákov e Iván radica en que ambos, en su ambiente propio, son personajes respetados, e incluso vistos como superiores. Aliosha, por ejemplo, considera que Iván se ocupa de una idea importante; todos lo tratan con respeto por su figura de intelectual. Smerdiákov, a su vez, es considerado por María Kondrátievna y su madre - ambas de su misma posición socialcomo alguien que les es superior.

En una segunda entrevista, Smerdiákov hace ver a Iván su deseo de asesinar a su padre, derivado del hecho de que, pese a saber el peligro que se cernía sobre Fiodor, lo dejó sin defensa alguna. Así le dice: "Matar, por nada 
del mundo podía hacerlo usted mismo, ni quería hacerlo; pero desear que otro matara, eso sí lo deseaba" (p. 740).

Iván comienza a atormentarse por su papel de asesino; si Smerdiákov mató a Fiodor, él sería el autor intelectual del crimen o, al menos, su facilitador. Al encontrar en Mitia al asesino, Iván quedaría libre de culpa. Por eso, al principio no sospecha en absoluto del lacayo y le parece tan absurdo que Aliosha crea en la inocencia de Dmitri.

Si quien mató no fue Dmitri, sino Smerdiákov, está bien claro que yo soy solidario suyo, pues le instigué. En realidad, no sé aún si le instigué. Pero si mató él y no Dmitri, desde luego, también yo soy asesino", razona Iván (p. 743).

Así, pese a considerar a su hermano culpable de la muerte del padre, Iván planea la huida de Dmitri, para tranquilizar su conciencia, que poco a poco le hace ver su participación en el parricidio: "¿Será porque en el fondo del alma soy yo también un asesino?" (p. 746), se pregunta.

En la última entrevista con el lacayo, en Iván se opera un cambio súbito: una decisión hace posible que su odio se transforme en solidaridad, en compasión.

Smerdiákov se revela como el asesino de Fiodor, pero alega que su acción estuvo justificada por las palabras de Iván ("Si Dios no existe, todo está permitido") y por su conducta (dejó al padre solo e indefenso). Vemos aquí la complejidad de la obra dostoievskiana; Raskolnikof, el protagonista de Crimen y castigo, elabora una teoría del hombre superior, que lo mueve a la acción y a matar a la vieja usurera. Iván expone su pensamiento, pero en este caso su idea depende de una condición (la no existencia de Dios), que en este ideólogo aparece irresuelta; otro -Smerdiákov- retoma esa idea, pero deja de lado su carácter condicional: él sólo escucha y actualiza el "todo está permitido". Raskolnikof es el autor material e intelectual del crimen de la vieja usurera (en Crimen y castigo); en Los Hermanos Karamázov se opera una escisión: Smerdiákov es el autor material del crimen, mientras Iván es el autor intelectual: "Mató usted [dice el lacayo], usted es el asesino principal. Yo fui tan sólo su secuaz, su fiel criado Licharda, y obré ateniéndome a sus palabras" (p. 750). 
Mientras el autor material del crimen se suicida, su autor intelectual se ve atormentado por el juicio divino. Iván, que en ningún momento ha dicho que Dios no existe (lo que sí ha dicho es que rechaza su plan de armonía), se debate, en este momento, entre su propia idea y la interiorización de la moral cristiana. Recordemos que se ha identificado a este ideólogo con Cristo - por su defensa de la libertad del individuo- $y$, a la vez, con la maldad que propicia el crimen, o sea, con la libertad vuelta contra sí misma.

Iván se asusta al ver las consecuencias de su planteamiento. Smerdiákov le dice: "Entonces era usted mucho más valiente, 'todo está permitido', decía; pero ahora, ¡vaya cómo se ha asustado!" (p. 752). Se sorprende, además, de ver cómo su idea es retomada por el lacayo para justificar el asesinato de Fiodor. Smerdiákov, además de cumplir el deseo oculto de Iván, pone en acción, con el fin de satisfacer sus ambiciones personales, esa que Rakitin había llamado antes una "seductora teoría para la gente vil".

Tenía primero la idea [apunta Smerdiákov] de que con este dinero empezaría la vida, en Moscú, o mejor aún en el extranjero, este era mi sueño, sobre todo porque 'todo está permitido'. Fue usted quien me lo enseñó, la verdad, pues entonces me decía muchas veces: si el Dios infinito no existe, tampoco existe ninguna virtud, ni falta que hace. Fue usted, en verdad. Y así razoné yo (p. 760).

Smerdiákov insiste en hacer que Iván vea su propia cobardía, enfrentándolo con sus propios temores y debilidades: "Usted mismo, enton-

ces, a cada paso decía que todo está permitido, y ahora, ¿por qué está tan alarmado? Hasta quiere ir a declarar contra sí mismo..." (p. 761).

Iván, en un momento fundamental de autoconciencia, se reconoce culpable del parricidio y decide declararlo así ante el jurado en el proceso seguido contra Mitia:

“Era el fin de todas las vacilaciones que tanto le habían atormentado durante aquel último tiempo!" (p. 762).

En ese momento de claridad, el joven Karamázov transforma su odio en compasión. Recoge a un pobre alcohólico a quien, antes de su entrevista con Smerdiákov, había golpeado y arrojado en la nieve. Ya no es aquel Iván que le confesaba a Aliosha su incapacidad para amar concretamente a cada prójimo. 
Sin embargo, este sentimiento de bienestar le durará poco. Iván entra poco después en una crisis nerviosa que lo hace enloquecer.

\section{Iván y el diablo}

La conversación de Iván con el diablo se puede ubicar en el plano de lo fantástico, característica que también aparece en otra pieza dostoievskiana: El doble. El otro que conversa con el personaje puede ser tanto una aparición como producto de la imaginación del personaje. No obstante, el narrador señala aquí que se trata de una pesadilla y la atribuye a la fiebre nerviosa que sufre Iván; al respecto, conviene señalar que el narrador de Los Hermanos Karamázov es una especie de cronista, al cual no se le puede otorgar la "verdad última" de los hechos narrados. Iván, en esta situación, no sabe si este intruso es él mismo, o si tiene existencia propia. Veamos lo que le dice a ese "otro":

A veces no te veo y ni siquiera oigo tu voz, como la otra vez, pero siempre adivino lo que vas a endilgar, porque ¡soy yo quien habla, yo mismo, y no tú!"” (p. 766).

Eres la encarnación de mí mismo, aunque, de todos modos, de una parte..., de la de mis pensamientos y sentimientos más asquerosos $\mathrm{y}$ estúpidos" (p. 767).

El diablo retoma las palabras de Iván, pero las parodia, dándoles un tono burlón. El diablo, como doble, le permite ver sus ideas sin darles la importancia que acostumbra. Por medio de su discurso, Iván reconoce su propia insignificancia: si él es el diablo, es un diablo incapaz de provocar temor; es, en fin, un pobre diablo.

En realidad, estás rabioso contra mí [le dice el diablo a Iván] por no haberme presentado con una aureola roja, 'entre rayos y truenos', con alas chamuscadas, en vez de venirte a ver vestido con tanta modestia. Sientes ofendidos, en primer lugar, tus sentimientos estéticos; en segundo lugar, tu orgullo: ¿cómo es posible, estarás pensando, que a un gran hombre semejante le visite un diablo tan vulgar?" (p. 779).

Lo que más atormenta a Iván en este momento es la decisión de declararse culpable de la muerte de su padre. Si bien en un momento anterior, justamente después de su última conversación con Smerdiákov, siente una tranquilidad interior que diluye todas las incertidumbres, ahora experi- 
menta un enorme temor ante su actitud; el diablo le dice que declarará porque es un hombre orgulloso, que quiere ser alabado. A su nuevo sentimiento de compasión, se opondrá su conciencia de individualista. Incapaz de conciliar este tipo de contradicciones, Iván Karamázov termina en la locura.

\section{Iván y Dmitri}

Mitia se muestra muy interesado por comprender lo que propone su hermano; constantemente le pregunta si todo está permitido. No solo a Iván, sino que también busca a Rakitin para salir de sus dudas.

A Dmitri también le preocupa la existencia de Dios, aunque está muy seguro de su incapacidad para asumir reflexiones de esta índole. Dice: “Iván no cree en Dios. Él cree en una idea. Esto sobrepasa mis dimensiones" (p. 714).

Mitia se pregunta acerca del sentido de la vida sin la inmortalidad. Contrario a su hermano Iván, es un hombre apasionado, capaz de hacerlo todo por la mujer amada.

En este sentido, Grushenka cumple un papel redentor; pese a ser condenado por las leyes humanas, Mitia se siente redimido por la posibilidad de vivir amando.

\section{Iván y Aliosha}

Aliosha no es ningún tipo de místico alejado de la realidad; tampoco es la personificación de la inocencia. Por el contrario, es un hombre consciente de los desenfrenos de los Karamázov y consciente también del dolor humano. En cierta medida, esto lo confunde, mas él no llega a romper con Dios.

Aliosha representa la solidaridad, es un hombre sensitivo. Iván es lo contrario: individualista, intelectual, frío.

Para Aliosha, el mal es producto del individualismo, del egoísmo: “En este amor propio [dice] se ha encarnado el diablo y se ha introducido en toda la generación, ha sido precisamente el diablo" (p. 673).

En una conversación con el niño Kolia, Aliosha comenta que la gente ha dejado de sentir la necesidad de autocensurarse. Él propone, pues, la necesidad de que las personas busquen el origen del mal, no solo en Dios, sino también en sus propias acciones, en su propia voluntad.

La creencia en Dios lleva, siguiendo el razonamiento del joven novicio, a la posibilidad de creer y amar al resto de los seres humanos. Por eso Iván, que no cree en nadie, termina despreciando 
a todos: "No desprecia a nadie -prosiguió Aliosha-. Solo que no cree en nadie. Claro que si no cree, desde luego, desprecia." (P. 705)

Mientras que Smerdiákov condena a Iván, su hermano lo perdona. Aquel le refleja al ideólogo sus más bajos pensamientos e intenciones; este, por el contrario, rescata de él sus buenos sentimientos, su capacidad para amar.

Sí, Iván; varias veces te has dicho a ti mismo que el asesino eres tú.

Te lo has dicho muchas veces mientras has estado solo durante estos dos meses terribles. Te has acusado y te has confesado de que nadie es el asesino, sino tú. Pero no has matado, tú te equivocas, no eres tú el asesino, ¿me oyes?, ¡no eres tú! Dios me ha mandado a mí a decírtelo (p. 725).

Aliosha disipa las pesadillas de Iván. Él lo conforta; ante todo, lo compadece por defender una idea en la cual no cree: “¡Dios vencerá -pensó-. O renacerá Iván a la luz de la verdad o... sucumbirá en el odio, vengándose a sí mismo y a todos por haber servido a una causa en la que no cree" (p. 788).
Alexiéi Karamázov puede transformar el dolor universal en un motivo para el amor. Acepta el plan divino y se propone cumplirlo entre los seres humanos. En cierta medida representa a ese Cristo capaz de solidarizarse con los pecadores, sin despreciarlos. La muerte del pequeño Iliusha -no la de los niños en general, como plantea Iván- lo lleva a proponer un plan fraternal. Ante el dolor, el amor, no el odio.

\section{REFLEXIONES FINALES}

Cada personaje ha corrido su suerte en función del diálogo con la idea de Iván Karamázov. La novela no nos narra sino el devenir, casi siempre tortuoso, de una idea en las vidas de los personajes. Ninguna acción se impone a los hermanos Karamázov por su propio peso: ellos actúan con libertad, al adoptar, cada cual a su manera, la idea de Iván.

Por eso Smerdiákov mata al viejo Fiodor: se siente autorizado por la idea de que "todo está permitido" y pone en marcha el crimen.

Dmitri, por su lado, se abstiene. Puede más, en él, el amor por la mujer. 
Aliosha logra transformar la idea de Iván en una moral. Termina pensando que el mal es la prueba de que Dios existe, pues demuestra que en la creación existe la libertad de la persona, que puede hacer el mal si lo desea. Si no viéramos el mal -diría Aliosha- sería porque no somos libres para hacerlo, ya que el ser humano es imperfecto y no sabe siempre cómo evitar obrar mal. Vemos el mal, en consecuencia somos libres, y esa libertad proviene de Dios.

Iván, finalmente, se ve atrapado en un error y por eso enloquece. $\mathrm{Su}$ error ha sido condenar a Dios por no tener moral y creer que sólo Dios puede establecerla, de modo que, en su ausencia, no hay moral. (Camus señala que el ateo debería, más bien, pensar que, en ausencia de Dios, nada está permitido: los seres humanos deben edificar su propia moral, siempre cambiante y relativa, pues no proviene de valores absolutos divinos.) Iván cree que la moral solo puede venir de Dios; hay en él algo de ese Gran Inquisidor que les niega la libertad a los seres humanos: la libertad para darse valores sin tener una autoridad divina que los respalde.
Con ese devenir de las ideas, la forma de composición de la obra dostoievskiana nos pone de manifiesto una sensibilidad necesaria al ser humano en esta época posmoderna, donde ha caducado la creencia en verdades absolutas (Araya, 1993): la escucha, el diálogo, la crítica y la discusión deben convertirse, hoy más que nunca, en una forma de vida para responder a un mundo que debe crearse nuevos valores.

\section{BIBLIOGRAFÍA}

Amoretti, María (1992). Diccionario de términos asociados en teoría literaria. San José: Editorial de la Universidad de Costa Rica.

Araya, Fernando (1993). En el eje del tiempo. La explosión postmoderna. San José: EUNED.

Bajtín, Mijaíl (1986). Problemas de la poética de Dostoievski. México: Fondo de Cultura Económica.

Berdiaev, Nicolás (1978). El espíritu de Dostoievski. Buenos Aires: Ediciones Carlos Lohlé, Buenos Aires.

Camus, Albert (1984). El hombre rebelde. Santo Domingo: Alfa Omega.

Cruz, Sonia (2000). Crimen y castigo, el lado de la madre. Los Hermanos Karamázov, el lado del padre. Recuperado el 17 de octubre del 2004 de http://www.psicomundo.com/costarica/coloquio/tolstoi.htm 
D'Alton, Cristina (1990). Lengua y literatura. Ensayos didácticos. San José: EUNED.

Dostoievski, Fedor (1983). Los Hermanos Karamázov. Barcelona: Bruguera.

Glucksmann, André (2002). Dostoievski en Manhattan. Madrid: Taurus.

Marchese, Angelo y Forradellas, Joaquín (2000). Diccionario de retórica, crítica y terminología literaria (sétima edición). Barcelona: Ariel.

Ujánova, Natalia (2003). Introducción. Dostoievski, F. Los Hermanos Karamázov. Madrid: Cátedra. 